\title{
Manifestaciones tomográficas extrapulmonares de TBC y algunas de sus complicaciones asociadas
}

\section{Extrapulmonary TB Tomography and some Associated Complications}

\author{
E. Gana ${ }^{1} \quad$ G. Schiappacasse ${ }^{2}$ \\ ${ }^{1}$ Clínica Indisa, Universidad Andrés Bello, Santiago, Chile \\ ${ }^{2}$ Clínica Alemana, Hospital Padre Hurtado, Santiago, Chile
}

Rev Argent Radiol 2018;82:28-35.
Address for correspondence E. Gana Gonzalez, Residente, Piedra Roja 1352 Dpto. C1, Clínica Indisa, Universidad Andrés Bello, Las Condes, Santiago, Chile (e-mail: e_gana_gonzalez1@hotmail.com).

\section{Resumen \\ Palabras Clave \\ - Tuberculosis \\ - Tomografía Computada \\ - Pulmón}

\section{Abstract}

received

June 23, 2016

accepted

December 23, 2017
La Tuberculosis (TBC) es una patología infecto-contagiosa de alta morbimortalidad en Chile y en el mundo, siendo la segunda causa de muerte por cuestión infecciosa y es considerada una patología de alta relevancia a nivel de salud pública. Es causada por una bacteria de alta virulencia y contagio llamada mycobacterium tuberculosis.

En la actualidad contamos con protocolos de detección y tratamiento muy eficaces, que la convierten en una enfermedad prevenible y curable. El diagnóstico se realiza con estudios bacteriológicos específicos frente a una sospecha clínica-epidemiológica sugerente. Sin embargo, el uso de imágenes forma parte casi obligatoria de su estudio y control. Debido a que el órgano diana de la TBC es el pulmón, es habitual utilizar como apoyo diagnóstico una radiografía de tórax, la cual es útil, en caso de TBC pulmonar, al presentar hallazgos característicos y orientadores para su diagnóstico. Es importante destacar que el mycobacterium tuberculosis tiene alto potencial de diseminación por contigüidad, vía linfática y/o hematógena, siendo esa última vía la causante de la mayoría de las TBC extrapulmonares, las cuales se presentan en un $20 \%$ de pacientes inmunocompetentes y hasta en un $60 \%$ de inmunocomprometidos. La principal localización de una TBC extrapulmonar es a nivel pleural, seguida del compromiso ganglionar, urogenital y osteoarticular, siendo el resto de las localizaciones muy infrecuentes. Para esos casos la tomografía computada (TC) es el estudio por imágenes de elección para el diagnóstico y control, además de ser una herramienta muy útil para la detección de complicaciones.

Tuberculosis (TB) is an infectious disease of high morbility and mortality in Chile and in the world. It is the second cause of death due to infectious causes in the world, and is considered of high relevance to public health. TB is caused by a highly pathogenic and virulent bacterium denominated mycobacterium tuberculosis. Nowadays, there are effective protocols for detection and treatment of this disease, which make it preventable and curable. Diagnosis is reached by specific bacteriological studies in the presence of a clinical epidemiological suspicion. Nevertheless, imagining methods
DOI https://doi.org/ $10.1055 / \mathrm{s}-0038-1637028$. ISSN 1852-9992.
Copyright ( 2 2019, Sociedad Argentina de Radiología. Publicado por Thieme Revinter Publicações Ltda., Rio de Janeiro, Brazil. Todos los derechos reservados.
License terms

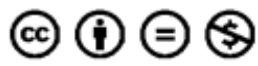




\author{
Keywords \\ - tuberculosis \\ - computed \\ tomography \\ - lung
}

are almost an obligatory part of tuberculosis study and control. Since the lung is the target organ of TB, chest X-ray is commonly used as a support for diagnosis, which is very useful in case of pulmonary TB because it provides characteristic findings to guide diagnosis. It is important to highlight that the mycobacterium tuberculosis has a high potential for dissemination by contiguity, via lymphatic and/or haematogenous, the latter being the cause of the majority of extrapulmonary TB, which are presented in $20 \%$ of immunocompetent patients and by up to $60 \%$ of immunocompromised. The main site of extrapulmonary TB is into the pleural space, followed by the lymph node, urogenital and osteoarticular involvement, the remainder being infrequent localizations. In these cases, a computed tomography (CT) study based on the selection of images, is the tool used for diagnosis and control, which is also useful for the detection of complications.

\section{Objetivo}

Realizar un ensayo iconográfico de los principales hallazgos tomográficos de la tuberculosis (TBC) $)^{1-6}$ con sus distintas manifestaciones, tanto pulmonares como extra pulmonares, además de presentar algunas complicaciones asociadas mediante una recolección de casos basados en nuestra experiencia.

\section{Desarrollo del tema}

Se presenta una revisión iconográfica de los principales hallazgos imagenológicos por TC (Tomografía computada) en TBC extrapulmonar reportados en la literatura y una serie de casos recolectados en la experiencia. Se agruparan los diferentes compromisos extrapulmonares como:

- Ganglionar:

- Escrófula cervical.

- Urogenital:

- Nefrourinarias.

- Osteoarticular.

- TBC miliar.

- Abdominal:

- Intestinal.

- Mesentérica.
- Esplénica.

- Endobronquial.

- Complicaciones:

- Tromboflebitis de vasos del cuello.

- Fístulas broncopulmonares.

\section{Compromiso ganglionar}

Después del compromiso pleural, es una de las localizaciones más comunes de la TBC extrapulmonar, la presentación cervical o supraclavicular es el grupo ganglionar más comúnmente afectado. ${ }^{7}$ El compromiso de adenopatías cervicales que se puede apreciar al examen físico, recibe el nombre de adenitis cervical tuberculosa o escrofulosis (- Fig. 1).

En TC, se aprecian linfonodos con un engrosamiento periférico y una atenuación hipodensa central (-Figs. 1 y 2). Esas imágenes son muy sugerentes de una TBC ganglionar, pero no es patognomónico, por lo que se debe tener en consideración diagnósticos diferenciales como metástasis, linfoma y patologías inflamatorias. ${ }^{8}$

La presentación ganglionar cervical o escrofulosis, puede tener variadas complicaciones, dentro de ellas destacan el compromiso de los vasos del cuello, debido a la contigüidad de ellos en relación a los grupos ganglionares, pudiendo presentar tromboflebitis de los principales vasos (-Fig. 3).
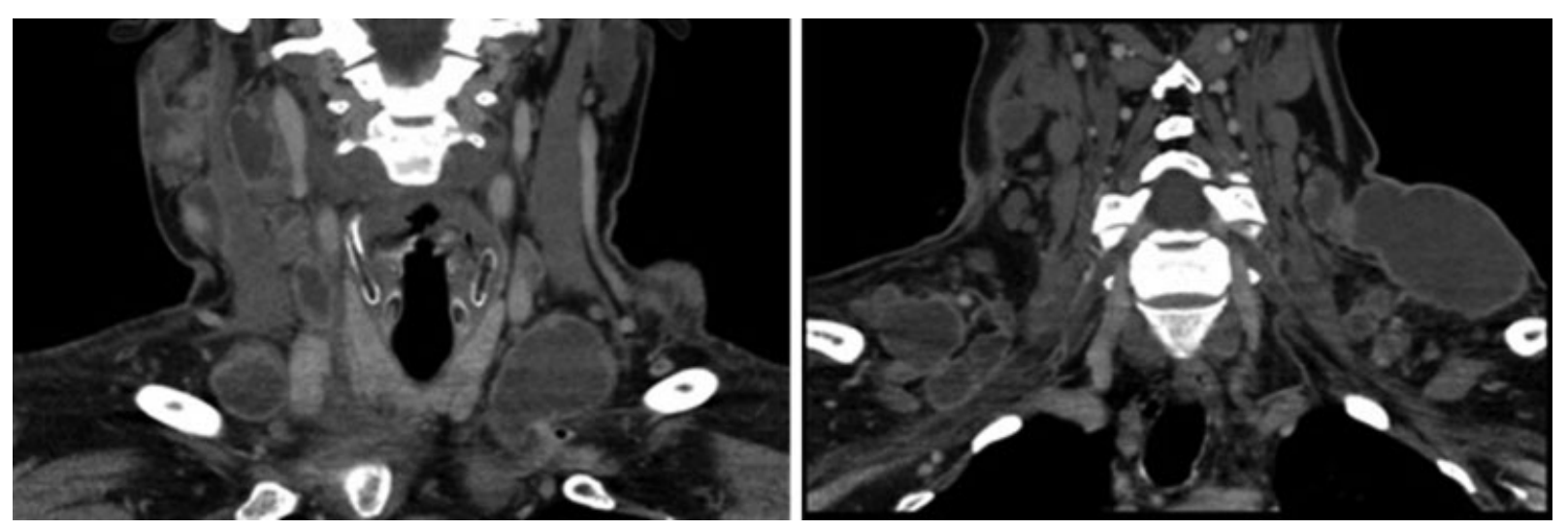

Fig. 1 Hombre con tumefacción no dolorosa en el cuello, mostró fiebre, diaforesis y baja de peso. Se realizó tomografía computada (TC) de región cervical, destacándose múltiples adenopatías con compromiso ganglionar con realce periférico y atenuación hipodensa central. Se realizó diagnóstico de adenitis cervical tuberculosa o escrofulosis. 


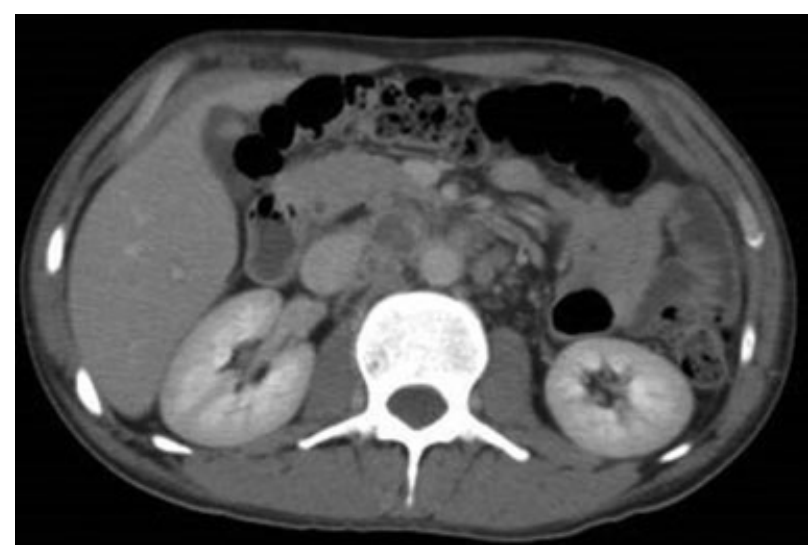

Fig. 2 Hombre con antecedentes de virus de inmunodeficiencia humana (VIH) sumado a tuberculosis (TBC) miliar, se realizó TC de abdomen por dolor abdominal. Se destacaron múltiples adenopatías peripancreáticas con refuerzo periférico y centro hipodenso, sugerentes por contexto clínico e imagen de TBC extrapulmonar.

\section{Compromiso urogenital}

La presentación genitourinaria es una de las principales localizaciones en pacientes con TBC extrapulmonar. Se ve afectado, principalmente el riñón, por diseminación hematógena desde los pulmones. 8,9

La alteración más precoz se aprecia a nivel de los cálices con erosiones en "apolillado". Ese hallazgo es seguido de una necrosis papilar. Se puede observar una falla renal y una dilatación del sistema pielocaliciliar ( - Fig. 4). Hallazgos como cavitaciones del parénquima renal o bien cicatrices fibróticas del parénquima se aprecian en estados más avanzados. Calcificaciones con distribución lobar se observan en estadios finales. ${ }^{8}$ Lesiones similares se pueden encontrar en pielonefritis xantogranulomatosa.

\section{Compromiso osteoarticular: Espondilitis tuberculosa}

El compromiso de la columna vertebral, conocido también como mal de Pott, es la localización más común de las TBC extrapulmonares en las presentaciones osteoartirulares, siendo responsable de hasta un 50\% de los casos de tuberculosis óseas. ${ }^{10}$ Es más prevalente el compromiso de las vértebras lumbares. La afección del disco vertebral se realiza por contigüidad. Es característico observar el compromiso predominantemente anterior del cuerpo vertebral, hallazgo muy útil para realizar un diagnóstico diferencial con la enfermedad metastásica. ${ }^{8}$ Puede encontrarse infección de estructuras paravertebrales, las cuales comprometen al músculo psoas mayor, resultando en ocasiones en abscesos de ese mismo (-Fig. 5). La TC y la resonancia magnética (RM) son las imágenes de elección para demostrar los pequeños focos de infección ósea y la extensión de la enfermedad. ${ }^{11}$

Los diagnósticos diferenciales para esos hallazgos en TC son variados, dentro de ellos destacan, metástasis neoplásicas, infecciones como brucelosis, infecciones fúngicas y sarcoidosis. ${ }^{8}$ Las imágenes de tórax, frente a síntomas sugerentes pueden presentar patrones característicos de TBC que ayuden a dilucidar el diagnóstico ( - Figs. 5g y $\mathbf{5 h}$ ).

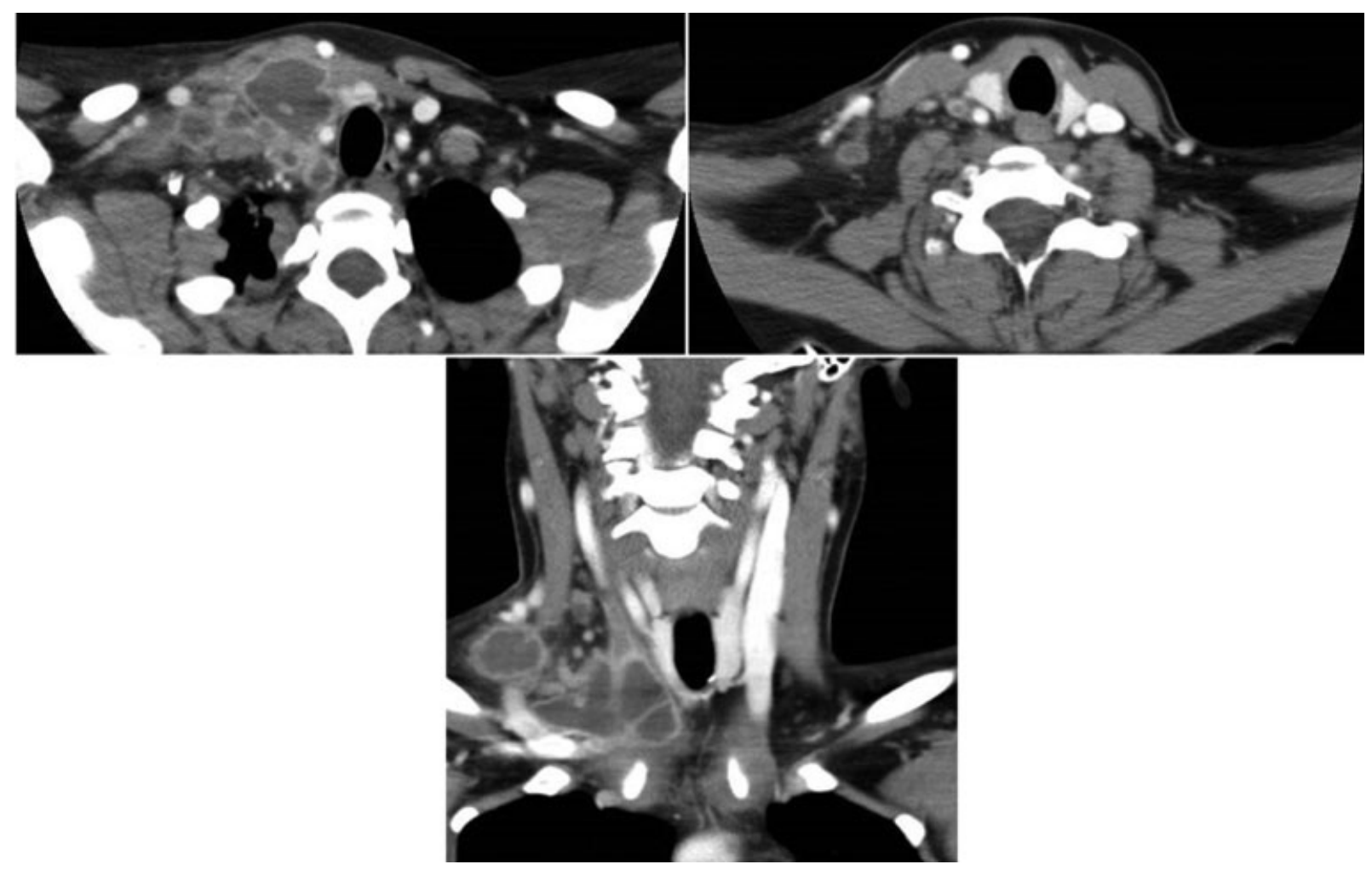

Fig. 3 Mujer con baja de peso, dolor cervical y fiebre. Presentó durante el examen físico, adenopatías supraclaviculares palpables. Se realizó TC de cuello, destacándose en la región supraclavicular derecha y paratiroidea ipsilateral un conglomerado de adenopatías de aspecto necrótico, abscedadas, que medían hasta $7 \mathrm{~cm}$ de diámetro mayor. Se identificó un trombo en la vena yugular interna derecha. 


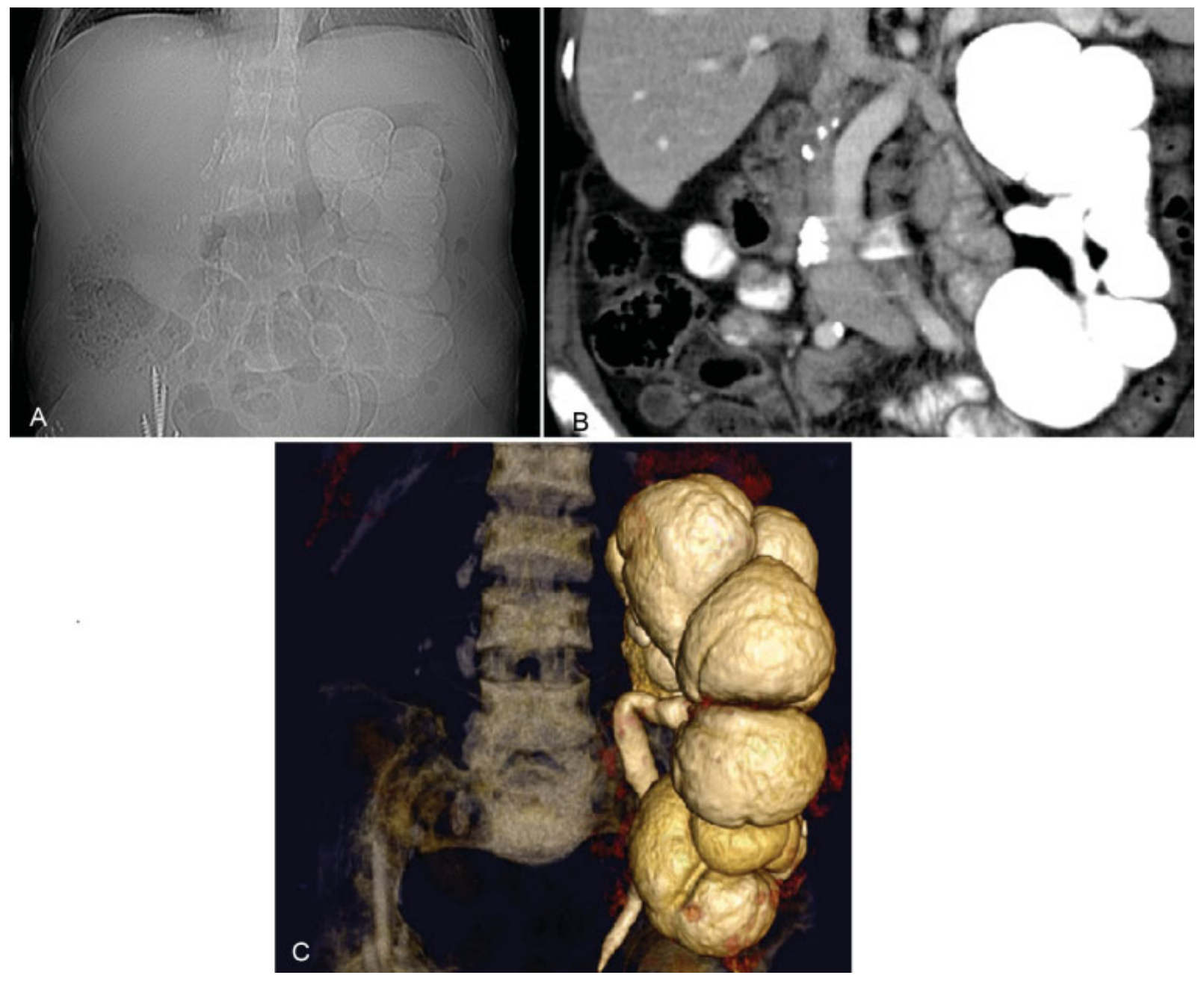

Fig. 4 Mujer de 44 años con antecedentes de TBC pulmonar, pleural y genitourinaria, nefrectomizada derecha, enfermedad renal crónica en hemodiálisis, realizó una consulta por dolor abdominal y crisis hipertensiva secundaria. (a y b) Se realizó TC que destacó una marcada dilatación del sistema caliciliar con destrucción caseosa cortical o corticomedular y del parénquima renal. (c) Se realizó una reconstrucción de TC en 3D que destacó con mayor énfasis las dilataciones mencionadas. En el examen de orina se aislaron bacilos de Mycobacterium tuberculosis.

\section{Compromiso miliar}

La TBC miliar afecta en un rango del $1 \%$ al $7 \%$ de los pacientes con todas las formas de presentación de TBC. Es usualmente vista en pacientes de edades extremas e inmunocomprometidos, la radiografía de tórax inicialmente puede ser normal, donde solo se aprecian signos de hiperinflación, los hallazgos más característicos son micronódulos de 2 a 3 mm ( - Fig. 6), con un predominio de hasta un $85 \%$ en lóbulos inferiores. ${ }^{12}$ En caso de dudas, la TC es más sensible, siendo el método de imágenes de elección para dilucidar el diagnóstico.

Generalmente el compromiso por TBC miliar, se resuelve con tratamiento sin dejar cicatrices o calcificaciones.

\section{Compromiso abdominal: TBC intestinal y esplénica}

En los pacientes con TBC abdominal, el compromiso a nivel ileocecal se presenta en un $80 \%$ a $90 \%$ de los pacientes. ${ }^{13}$ En TC, la mitad de los pacientes con tuberculosis gastrointestinal muestran engrosamiento circunferencial del ciego e íleon terminal, ampliación de la válvula ileocecal, y linfoadenopatías mesentéricas (-Fig. 7). ${ }^{8}$ Hallazgos como la asimetría de la válvula ileocecal, engrosamiento de la pared medial del ciego, la extensión exofítica e inmersión del íleon terminal, asociado a múltiples adenopatías son más sugestivos de tuberculosis. $6,13,14$

El compromiso esplénico de la TBC generalmente se manifiesta en pacientes con TBC miliar, y puede presentarse en forma de micronódulos o macronódulos a nivel de bazo o hígado. En la TC, se identifican múltiples micronódulos hipodensos de distribución difusa de 1 a $3 \mathrm{~cm}$ de diámetro ( - Figs. 8 y 9), la forma macronodular o tuberculoma es rara de encontrar. ${ }^{6,8,14}$ El diagnóstico diferencial en la forma micronodular incluye metástasis, infección fúngica, sarcoidosis y linfoma. La forma macronodular puede confundirse con metástasis, tumor maligno primario, o absceso piogénico. ${ }^{8}$

\section{Diseminación endobronquial: complicaciones por cavitaciones y fístulas broncopulmonares}

Una de las complicaciones en la historia natural de la enfermedad por $\mathrm{TBC}$, es la diseminación endobronquial, la cual puede presentar múltiples complicaciones, dentro de ellas destacan las cavitaciones por destrucción del parénquima pulmonar y fístulas broncopulmonares. 

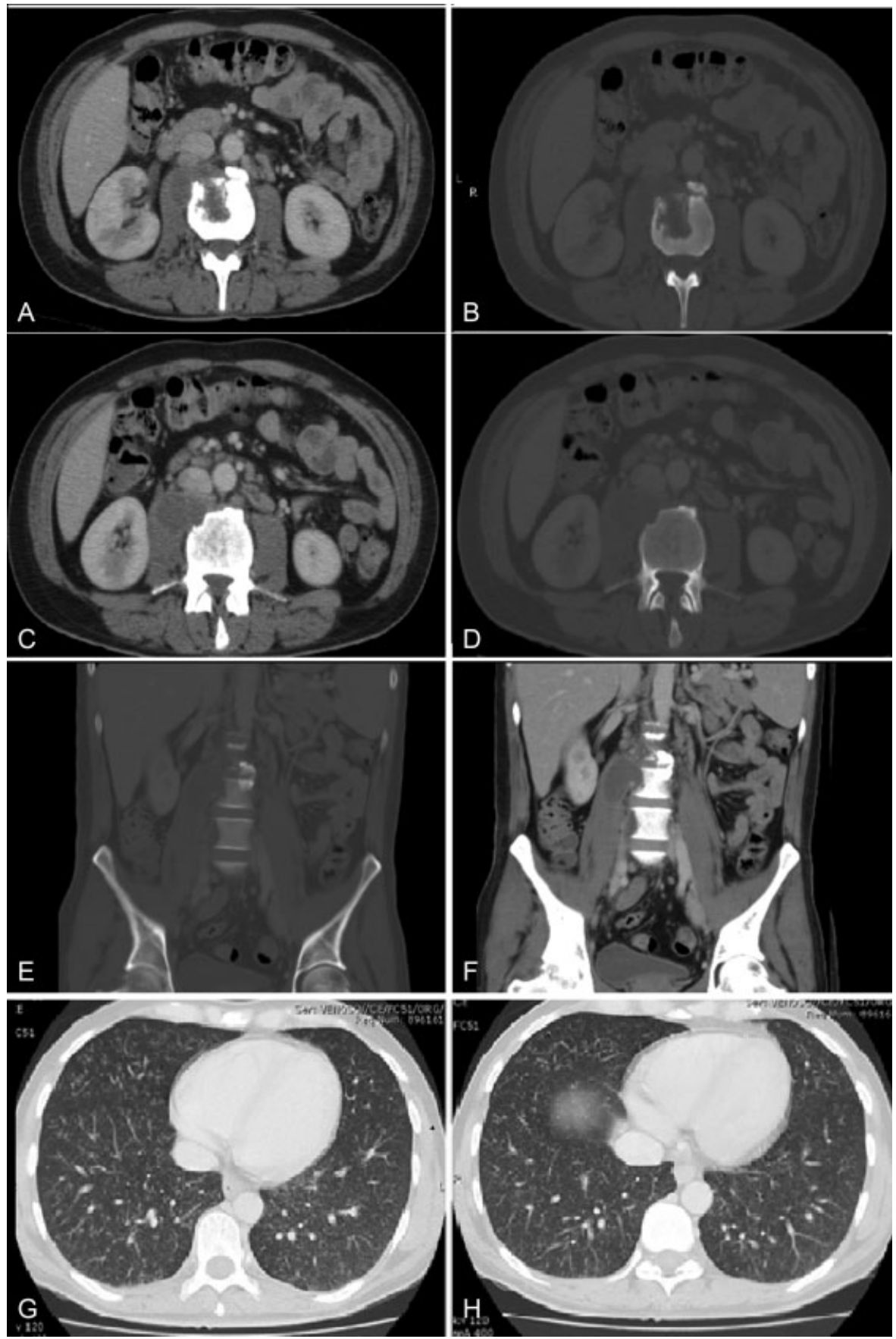

Fig. 5 Paciente hombre, 36 años, con antecedentes de VIH, consultó por dolor y aumento de volumen testicular bilateral de aproximadamente 2 meses de evolución, se solicitó TC de abdomen y pelvis por sospecha de tumor testicular. (a, b, c y d) Lesión hipodensa en relación al músculo psoas, con realce periférico de sus bordes, y que parece venir de una lesión osteolítica bien definida que afecta el borde anterior del cuerpo vertebral de L2-L3. (e y f) En el reformateo coronal se puede ver compromiso del disco intervertebral con disminución del espacio discal L2-L3. ( $\mathrm{y}$ h) Imágenes predominantemente nodulares centro lobulillares, algunas de ellas con ramificaciones en patrón de árbol en brote, características de TBC.

Las cavitaciones tuberculosas ocurren más comúnmente en áreas de consolidación e indican muy sugerentemente que se encuentra una infección activa, son a menudo múltiples y de paredes irregulares y gruesas (-Figs. 10, 11 y 12). ${ }^{15-17}$ Es extraño encontrar niveles hidroaéreos, pero cuando se hallan, sugieren la posibilidad de una sobreinfección (-Fig. 10). ${ }^{18,19}$
El curso natural de la enfermedad progresa a compromiso lobar y opacidades pulmonares casi completas, asociado a destrucción parenquimatosa (-Fig. 11), se produce la llamada enfermedad fibroproliferativa, con engrosamientos reticulares y nodulares. ${ }^{17}$

La diseminación endobronquial es la complicación más común causante de las cavitaciones tuberculosas, que 

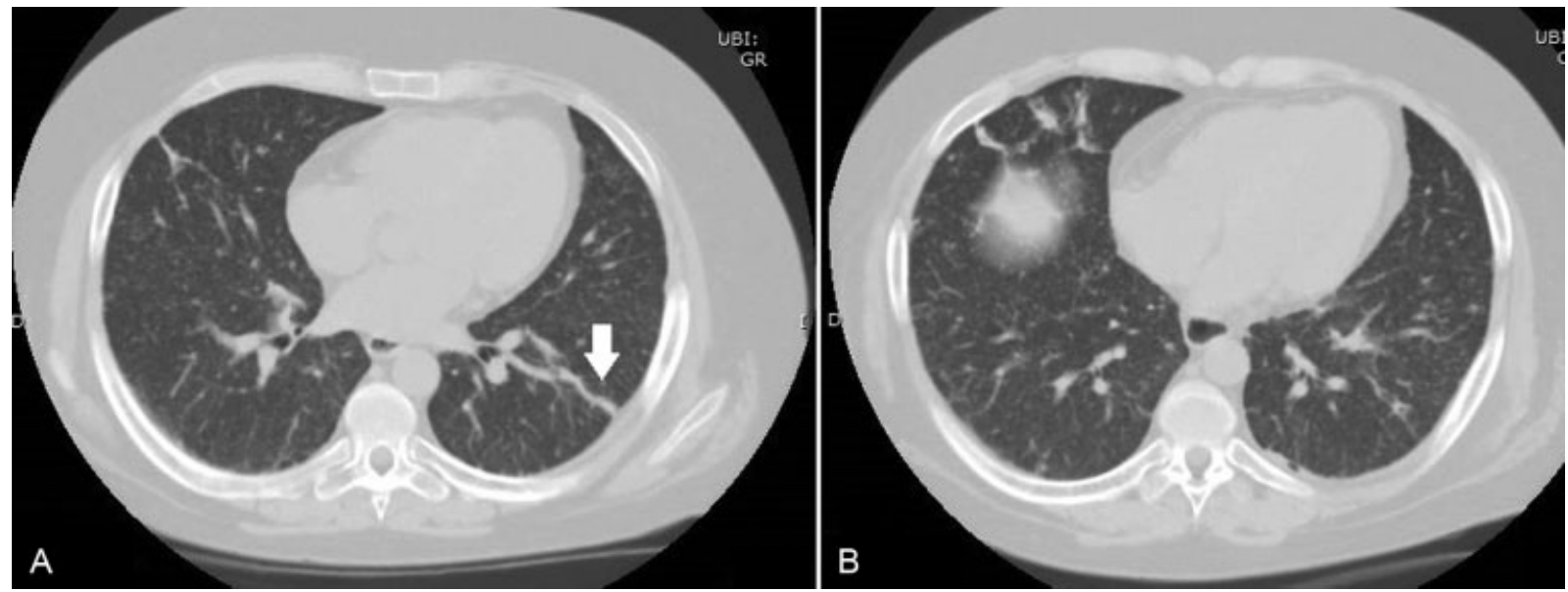

Fig. 6 Mujer con antecedentes de lupus eritematoso sistémico en tratamiento con inmunosupresores, hospitalizada por sospecha de neumonía. Se realiza TC de tórax donde destacan: ( a y b) múltiples micronódulos de distribución difusa en parénquima pulmonar. También se visualizaron algunos nódulos bilaterales, de bordes mal definidos. (a) Se visualizaron algunas imágenes lineales hiperdensas de aspecto cicatricial (flecha), que comprometen principalmente las bases pulmonares en sus porciones periféricas.
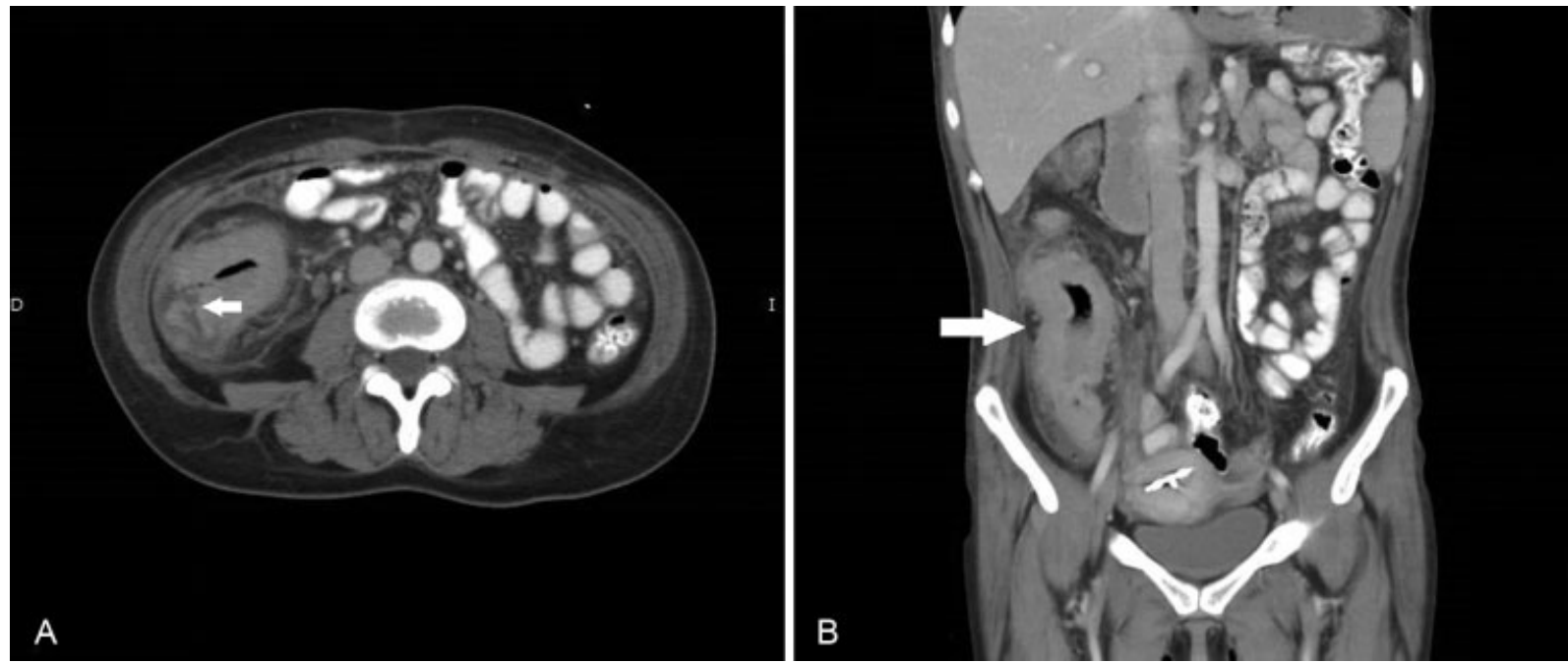

Fig. 7 Mujer de 40 años hospitalizada por sospecha de TBC intestinal, se solicita TC que destacó: (a) severo engrosamiento parietal difuso y concéntrico del íleon distal, que no estenosa significativamente el lumen y compromete la válvula ileocecal (flecha). Existe aumento de densidad de la grasa mesentérica y pericecal adyacente con pequeñas adenopatías de baja densidad de la cadena ileocólica que miden hasta $8 \mathrm{~mm}$ de diámetro. (b) La pared intestinal alcanza un espesor de $13 \mathrm{~mm}$ y realza en forma homogénea por contraste.
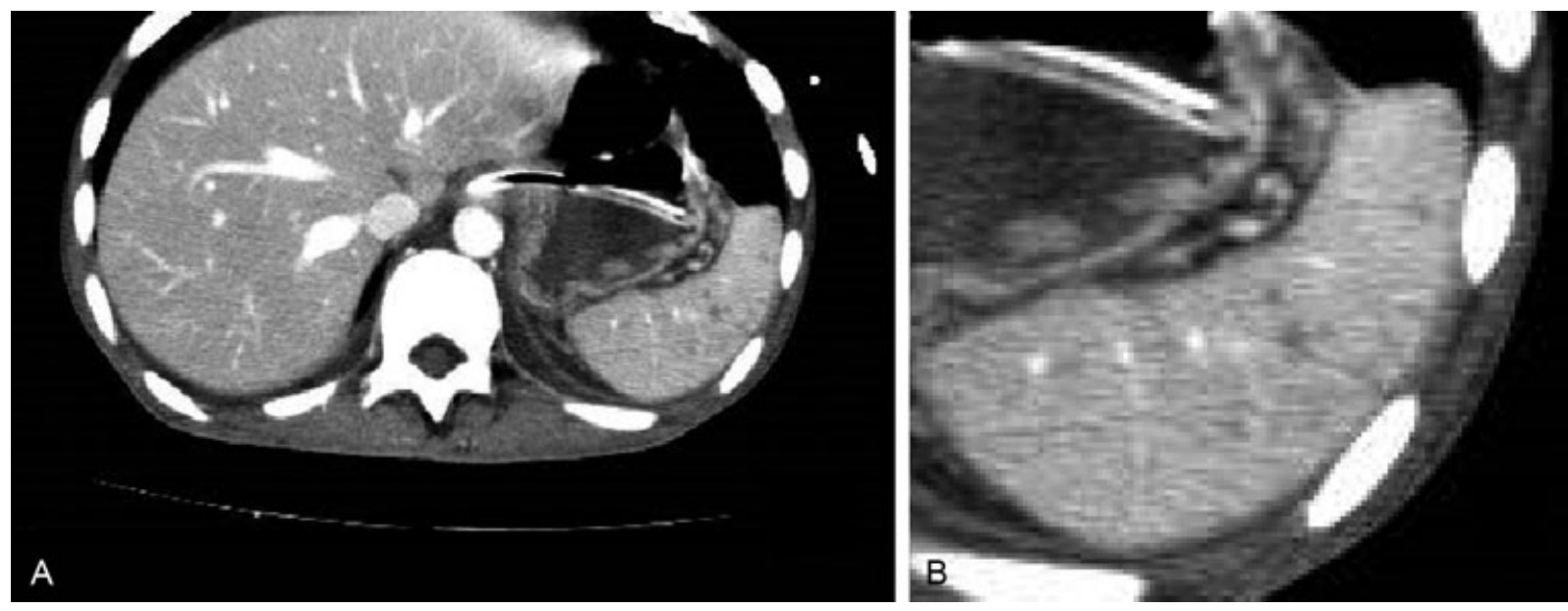

Fig. 8 Hombre de 36 años, con antecedentes de TBC miliar. Múltiples adenopatías y cuadro febril, se solicitó TC de abdomen y pelvis. (a) Compromiso micronodular múltiple hipodenso en bazo de carácter miliar. (b) Ampliación de micronódulos, el mayor mide $1 \mathrm{~cm}$. 

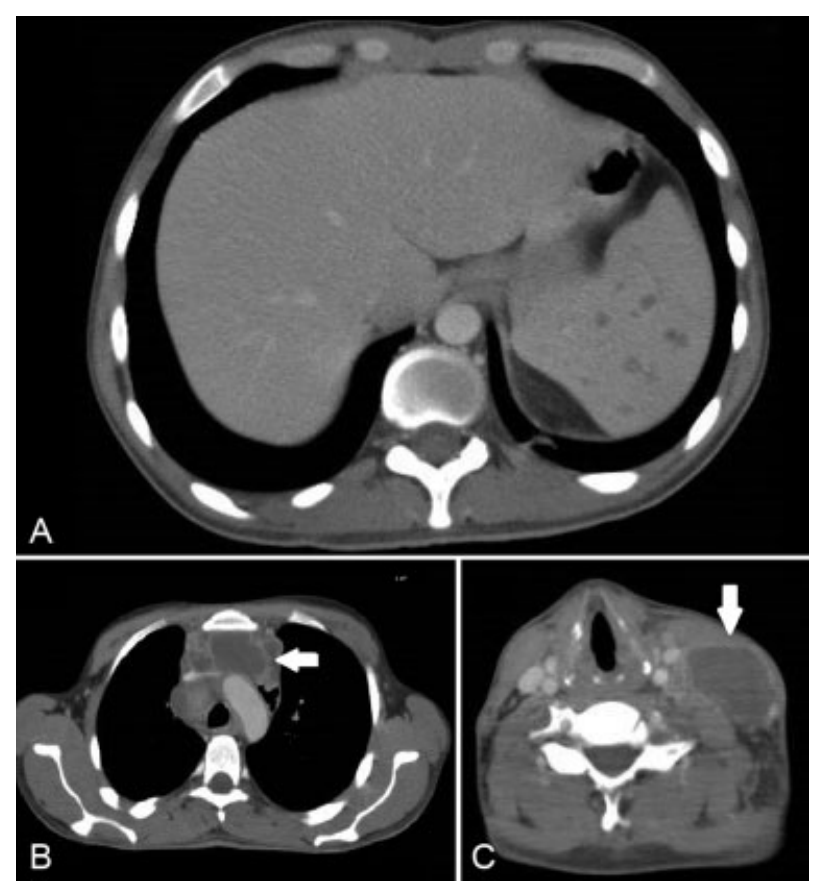

Fig. 9 Hombre de 27 años, con VIH, se realizó estudio por tumor cervical al examen físico. Se realiza TC que destacó: (a) múltiples imágenes hipodensas esplénicas compatibles con microabscesos de diámetros fluctuantes entre 1 y $2 \mathrm{~cm}$, de distribución difusa, (b) se observaron grandes conglomerados de adenopatías a nivel mediastínico peritraqueal, subcarinales y prevasculares, alcanzando en ese último un diámetro axial máximo de $8 \mathrm{~cm}$ (flecha) y (c) múltiples adenopatías cervicales en ambas cadenas yugulares y en el espacio cervical posterior izquierdo. Ellas presentaron centro hipodenso con realce periférico con el medio de contraste. La de mayor tamaño en el espacio cervical posterior izquierdo midió aproximadamente $4,5 \times 2,7 \mathrm{~cm}$ en sus ejes transversos máximos (flecha).

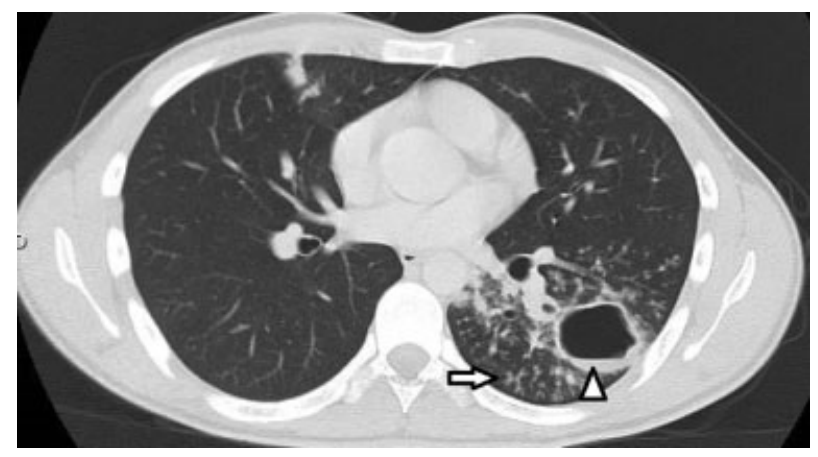

Fig. 10 Hombre de 23 años, con cuadro febril, tos y expectoración, se solicitó TC en sospecha de TBC complicada. Se observaron opacidades nodulillares centrilobulares asociados a una lesión nodular cavitada en el lóbulo inferior izquierdo con prominentes infiltrados peribronquiales tipo "árbol en brote" (flecha) y una lesión cavitada (triángulo) de contornos irregulares que midió aproximadamente $4 \mathrm{~cm}$ de diámetro y presentó un nivel hidroaéreo en su interior.

representan una infección granulomatosa crónica en la cual los organismos activos extienden una necrosis caseosa de las paredes bronquiales ( - Figs. 10 y 11).$^{17}$ Los hallazgos en TC se manifiestan como opacidades pequeñas y mal definidas, nodulillares centrilobulares sugiriendo la apariencia de un “árbol en brote" (-Figs. 10, 11 y 12). ${ }^{20,21}$
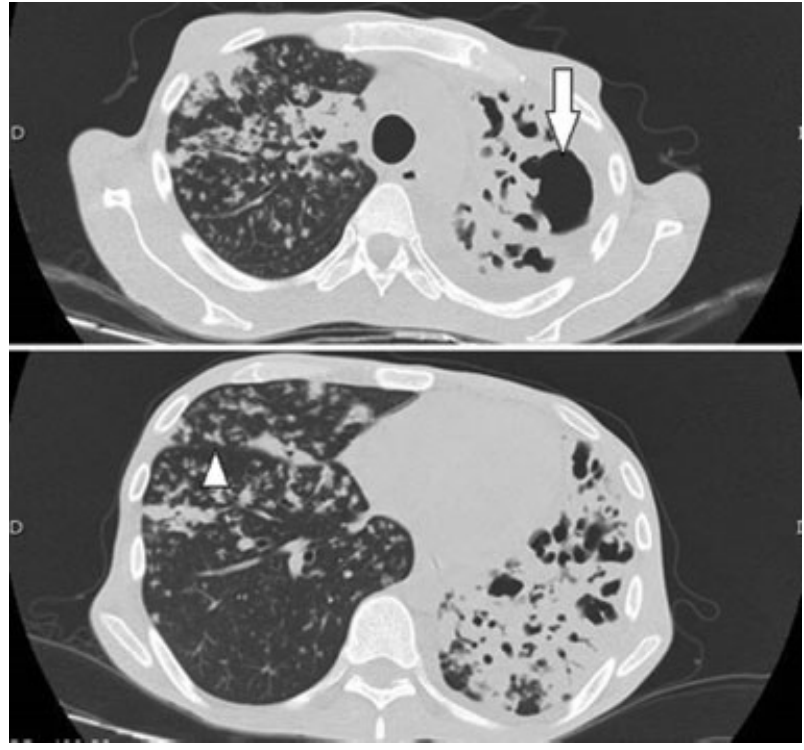

Fig. 11 Hombre de 32 años, con antecedentes de TBC pulmonar, con reactivación de su cuadro, se solicitó TC de tórax, donde se destacó: pulmón izquierdo disminuido de volumen con severa distorsión de la arquitectura pulmonar, con bronquiectasias varicosas y un mínimo remanente de parénquima normal en el lóbulo inferior izquierdo, se aprecian cavitaciones de distintos tamaños (flecha). En el pulmón derecho persisten imágenes de “árbol en brote" (triángulo), asociado a opacidades pulmonares y focos de condensación. Derrame pleural laminar a izquierda.

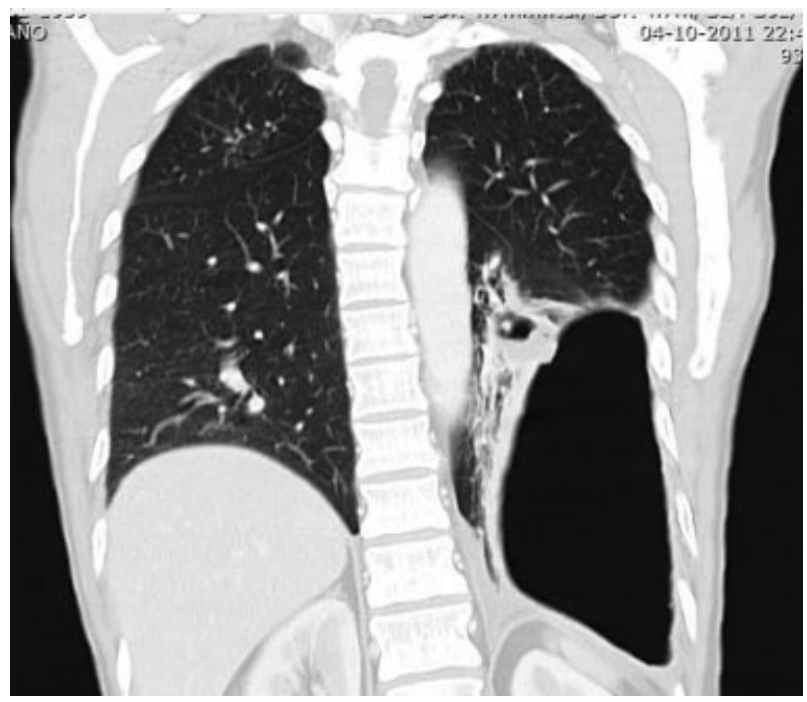

Fig. 12 Hombre de 51 años, con antecedentes de un empiema por TBC complicada. Se solicitó TC de tórax que destacó: en relación al lobo inferior izquierdo se apreció gran cavitación con fístula broncopulmonar comunicante, paredes engrosadas en relación a bronquiectasias periféricas e imágenes hiperdensas cicatriciales. Se observaron opacidades nodulillares centrilobulares con prominentes infiltrados peribronquiales tipo "árbol en brote."

Esas imágenes son características, pero no patognomónicas de TBC activa, el diagnóstico diferencial es amplio, incluyendo: infecciones fúngicas, parasitarias, aspergilosis alérgica broncopulmonar, fibrosis quística, neumonitis por aspiración y neoplasias raras como papilomatosis laringotraqueal y la mayoría de patologías que involucren vías aéreas pequeñas. ${ }^{17,21}$ 
Confidencialidad de los datos

Los autores declaran que han seguido los protocolos de su centro de trabajo sobre la publicación de datos de pacientes y que todos los pacientes incluidos en el estudio han recibido información suficiente y han dado su consentimiento informado por escrito.

\section{Bibliografía}

1 Organización Mundial de la Salud web. Disponible en: http://www. who.int/mediacentre/factsheets/fs104/es/Tuberculosis.(accedido Abr 2014)

2 Espitia C, Mancilla R. Identification, isolation and partial characterization of Mycobacterium tuberculosis glycoprotein antigens. Clin Exp Immunol 1989;77(03):378-383

3 Fanlo P, Tiberio G. Tuberculosis extrapulmonar. An Sist Sanit Navar 2007;30(Suppl 2):143-162

4 Kim MH, Yang HY, Suh JT, Lee HJ. Comparison of in-house PCR with conventional techniques and Cobas Amplicor $\mathrm{M}$. tuberculosis kit for detection of Mycobacterium tuberculosis. Yonsei Med J 2008;49(04):537-544

5 Pontificia Universidad Javeriana web. Disponible en: http://javeriana. edu.co/biblos/tesis/ciencias/tesis319.pdf. (accedido Ene 2018)

6 Leder RA, Low VH. Tuberculosis of the abdomen. Radiol Clin North Am 1995;33(04):691-705

7 Hopewell PC. A clinical view of tuberculosis. Radiol Clin North Am 1995;33(04):641-653

8 Engin G, Acunaş B, Acunaş G, Tunaci M. Imaging of extrapulmonary tuberculosis. Radiographics 2000;20(02):471-488, quiz 529-530, 532
9 Wang LJ, Wong YC, Chen CJ, Lim KE. CT features of genitourinary tuberculosis. J Comput Assist Tomogr 1997;21(02):254-258

10 Moon MS. Tuberculosis of the spine. Controversies and a new challenge. Spine 1997;22(15):1791-1797

11 Yao DC, Sartoris DJ. Musculoskeletal tuberculosis. Radiol Clin North Am 1995;33(04):679-689

12 Burrill J, Williams CJ, Bain G, Conder G, Hine AL, Misra RR. Tuberculosis: a radiologic review. Radiographics 2007;27(05):1255-1273

13 Balthazar EJ, Gordon R, Hulnick D. Ileocecal tuberculosis: CT and radiologic evaluation. AJR Am J Roentgenol 1990;154(03):499-503

14 Jadvar H, Mindelzun RE, Olcott EW, Levitt DB. Still the great mimicker: abdominal tuberculosis. AJR Am J Roentgenol 1997; 168(06):1455-1460

15 Woodring JH, Vandiviere HM, Fried AM, Dillon ML, Williams TD, Melvin IG. Update: the radiographic features of pulmonary tuberculosis. AJR Am J Roentgenol 1986;146(03):497-506

16 Kuhlman JE, Deutsch JH, Fishman EK, Siegelman SS. CT features of thoracic mycobacterial disease. Radiographics 1990;10(03):413-431

17 Harisinghani MG, McLoud TC, Shepard JA, Ko JP, Shroff MM, Mueller PR. Tuberculosis from head to toe. Radiographics 2000; 20(02):449-470, quiz 528-529, 532

18 Miller WT, Miller WT Jr. Tuberculosis in the normal host: radiological findings. Semin Roentgenol 1993;28(02):109-118

19 Makanjuola D. Fluid levels in pulmonary tuberculosis cavities in a rural population of Nigeria. AJR Am J Roentgenol 1983;141(03): 519-520

20 Im JG, Itoh H, Shim YS, et al. Pulmonary tuberculosis: CT findingsearly active disease and sequential change with antituberculous therapy. Radiology 1993;186(03):653-660

21 Collins J, Blankenbaker D, Stern EJ. CT patterns of bronchiolar disease: what is “tree-in-bud"? AJR Am J Roentgenol 1998;171(02):365-370 